Article

\title{
Leveraging Smart Open Innovation for Achieving Cultural Sustainability: Learning from a New City Museum Project
}

\author{
Luisa Errichiello * (D) and Roberto Micera \\ Institute for Research on Innovation and Services for Development (IRISS)—National Research Council (CNR), \\ Via G. Sanfelice, 8, 80134 Napoli, Italy; r.micera@iriss.cnr.it \\ * Correspondence: 1.errichiello@iriss.cnr.it; Tel.: +39-081-247-0967
}

Received: 20 April 2018; Accepted: 8 June 2018; Published: 12 June 2018

\begin{abstract}
In recent years, cultural sustainability has attracted increasing attention within the discourse of sustainable development and sustainable cities. Notwithstanding some effort put on conceptualizing the relationship between culture and sustainability, research on the issue is still in a pre-paradigmatic stage and related empirical studies are scant. In particular, further knowledge is required to understand not only how cultural sustainability has been addressed strategically but also implemented in practice. In this direction, research has pointed out the role of social structures (e.g., partnerships, collaborations, etc.) for achieving cultural sustainability goals. However, focusing on smart cities, attention is limited to how collaborative arrangements can be leveraged within the development of new city services (e.g., smart open innovation) to sustain goals of environmental, economic and social sustainability, with cultural sustainability still playing a marginal role. This paper develops a new framework linking together the strategic level and the practice level in addressing cultural sustainability and conceptualizing the role of collaborative structures in the development of smart innovation. The framework is then used as a frame of reference for analyzing the case of MuseoTorino, a new city museum realized within the smart city strategy of Turin (Italy). The analysis provides evidence of some practices adopted to leverage collaboration and stakeholders' engagement to strategically address cultural sustainability and to realize it in practice throughout the new service development process.
\end{abstract}

Keywords: cultural sustainability; smart city; open innovation; new city museum planning; case study

\section{Introduction}

Over the last decade, cultural sustainability, largely intended as the conservation and preservation of cultural capital [1,2], has emerged as a key topic of interest among different disciplines and contexts, such as public planning [3], urban development [4-7], sustainable development [8,9] and cultural policies [10-12]. Both at international and urban level the issue has attracted the attention of governments, companies and civil society organizations, which are increasingly recognizing the key role of culture in the implementation of national and local development strategies [4,13-15]. In this context, in particular, cultural organizations institutionally committed to cultural heritage preservation have been emphasized as engines of sustainability goals for economic development, social cohesion and environmental preservation for regions and cities [16].

For a long time, cultural sustainability has been mostly missing within the historical debate about sustainable development [2]. Sustainable development has become-as the United Nations' recent document (2015) clearly demonstrated-a serious normative principle in regulating contemporary 
societies to achieve socially good and ethically acceptable attributes, notably safeguarding long-term ecological sustainability, satisfying basic human needs, and promoting inter- and intra-generational social equity $[17,18]$. Within the broad debate on sustainability, the most influential models only consider environmental, social, and economic aspects as fundamental dimensions with no serious role attached to the cultural aspects of life and society by organizations and governments $[11,19,20]$. This under-appreciation of culture persisted over time also after the initial emphasis on environmental issues was discarded and economic and social issues were recognized as equally important in the sustainability framework [21-23]. Indeed, in that case the focus simply shifted on the need for balancing the three pillars of environmental, social, and economic sustainability, while culture was exclusively viewed as part of the broader "social" pillar [24-26]

Recently, an increasing number of scholars have started to theorize the role of culture within the sustainability paradigm and have emphasized its importance from a policy [19,27-29] and organizational perspective $[16,29,30]$. However, the main effort has hitherto been made at the conceptual level, with some theoretical frameworks elaborated for clarifying the role of culture in sustainable development and to understand its relation to social, economic and environmental sustainability $[29,30]$. Even when the attention shifts at practice level, available (and still scanty) research limited attention to the identification of a set of indicators that can be used by cultural institutions, like museums, to measure their sustainability levels in all the spheres, i.e., the cultural, economic, social and natural environment [16,31]. However, further knowledge is required to understand how cultural sustainability has been implemented in practice, especially by exploring the role of social structures (e.g., partnerships, collaborations, etc.) [29].

In the recent debate about the smart cities [32-34], these social structures have received the attention of scholars and practitioners, since many smart city innovation projects have been carried out relying on collaborative models and the involvement of a number of different city stakeholders, including citizens [35-38]. However, state-of-the-art research has hitherto focused on the benefits that smart open innovation can bring to cities in terms of environmental, economic and social sustainability, while ignoring the role that collaborative arrangements (e.g., associations, partnerships, etc.) based on multiple stakeholder engagement can play in fostering cultural sustainability goals.

This article extends previous research on cultural sustainability and smart open innovation by proposing a new framework that links together the strategic level and the practice level in addressing cultural sustainability goals and conceptualizing the role of collaborative structures in the development of smart innovation. Subsequently, the theoretical model is used as a frame of reference for analyzing a case study $[39,40]$ of an innovation project oriented at the development of a new city museum, i.e., MuseoTorino, in the context of an Italian smart city: Turin. The analysis, in particular, provides empirical evidence of a number of practices adopted at project level to achieve cultural sustainability goals during the development and delivery of the new smart city service.

This paper, in particular, sheds light on how collaborative structures, i.e., partnerships, informal arrangements and multiple stakeholders' engagement, can be leveraged to strategically address cultural sustainability goals and to realize it in practice both during the development stage and after the launch of the new city museum. This process, in particular, can be achieved through the mobilization - through these social structures—of a variety of tangible and intangible resources, including funding, specialized skills, complementary competences and innovative technologies. Paradoxically, although the smart city has been framed as the most advanced model of a sustainable city, the over-emphasis on technology has contributed to the under-appreciation of the value of culture and cultural institutions within the city sustainability development agenda. In this respect, this paper also aims at restoring the role of cultural sustainability within the discourse of smart cities.

This paper is structured as follows: The first part synthesizes the most relevant knowledge about cultural sustainability. Moreover, through contextualizing the debate in the context of smart cities, it proposes a new framework that addresses the cultural dimension both at strategic and practice level throughout the development of a new cultural service. The second part describes the qualitative 
methods adopted and the empirical results of the case study analysis. The final section proposes a discussion of results together with conclusions, including limitations and future research opportunities.

\section{Theoretical Background}

\subsection{The Surge of "Culture" in the Sustainability Debate: Moving Towards Strategy in Practice}

To explain the term "cultural sustainability", some authors [1,41] focus their attention on the three main roles of culture within the sustainability development paradigm that correspond to different representations: (1) culture in sustainability; (2) culture for sustainability and (3) culture as sustainability. The first representation points to cultural sustainability as an independent pillar (i.e., the fourth) to be considered next to ecological, social and economic ones. The second representation, that reflects the prevalent approach, points at material and immaterial culture only as instrumental to other pillars (e.g., ecologic, social and economic) that are considered more important. Culture as sustainability, which is more difficult to realize in practice, considers sustainability as embedded in culture and leading to eco-cultural civilization. In this work, we embrace and focus on "culture in sustainability", since this representation reflects a relevant advance made towards restoring the value of culture within the broader sustainability agenda [19-42].

Being mainly concerned with informing policymaker's actions for the sustainable development of cultural heritage organizations (i.e., museums), [30] consider cultural sustainability in narrowed terms, defining it as the conservation and preservation of cultural capital, i.e., "tangible and intangible heritage, artistic production, as well as the knowledge and skills of various social groups, communities, and nations" (p. 569). Drawing on the position that culture is an independent fourth pillar, the authors elaborate a theoretical model for the sustainable development of museums that considers sustainability as the intersection of four circles, corresponding to the pillars of cultural, environmental, social and economic dimensions [43]. For each pillar, the authors identify specific issues (named "parameters") that can be used both by cultural policy-makers and cultural professionals for understanding the complexity of the phenomenon and orienting their actions and strategies [14,42].

Two aspects related to Stylianou-Lambert et al.'s framework (2014) [30] are particularly relevant for our argument. First, specific parameters attributable to the cultural sphere can be divided into two main sub-groups, reflecting different strategic approaches and orientations underlying cultural policies or management, notably a "custodial" or "service" orientation and a "customer" or "market" orientation", respectively [44,45]. Although complementary, tensions exist between these approaches/orientations so that they are often considered as competing and adopted in an exclusive manner by cultural policy makers and cultural heritage organizations. In this regard, an emphasis towards issues included in the first sub-group, i.e. heritage preservation; transfer of cultural skills/knowledge; and construction and promotion of a sense of memory and identity, can be immediately associated to the classic mission of cultural heritage organizations of custody, preservation and education, reflecting the predominance of a "custodial" or "service" orientation [46-48]. This is aimed at fulfilling the museum's mission, focusing on quality and custody and it underlies an "object-oriented" approach in implementing cultural sustainability [30]. On the contrary, when emphasis is put on parameters of: the inclusion/development of a new audience; promotion of cultural diversity; intercultural dialogue; and encouragement of creativity, innovation and artistic vitality, this is more directly related to the adoption of a "customer-oriented perspective" along with a "people-approach" to cultural sustainability [30]. This is aimed at increasing visitor satisfaction through better accessibility to cultural resources, improved service experiences, direct involvement, and participation of the public in co-creation processes [46,49].

Another relevant aspect related to a sustainability framework based on four equally important pillars [30] is the acknowledgement that although each of them maintains its own autonomy, identity and value, they are interdependent. This argument is particularly important in relation to the traditional understanding of cultural sustainability only as a part of the broader social sustainability 
pillar [24-26]. In this regard, the model emphasizes that parameters respectively associated to the cultural and social sustainability spheres can be closely related, as it happens for cultural diversity and active citizenship, to cite an example. Notwithstanding their interdependence, however, these parameters remain distinctive strategic goals of equal importance within distinctive pillars.

At organizational level, a different but complementary relationship between cultural and other pillars of sustainability has been later elaborated [29]. Indeed, considering the environment of heritage organizations (and in particular of museums and libraries), the authors suggest to shift the attention on how social, economic and environmental structures work to support these organizations in achieving goals of cultural sustainability. As for the social sphere, in particular, this refers to the role of external agents, like associations and local institutions, especially acting through network and collaborative arrangements, in sustaining the achievement of cultural sustainability goals.

In our argument, re-framing the four sustainability pillars so that economic, environmental and social structures are conceptualized as means for implementing cultural sustainability-oriented strategies, seems to be more appropriate when heritage organizations have to move from the strategic to the practice level. At this level they have to deal with the implementation of specific practices and the mobilization of dedicated resources for achieving the stated goals within all the four areas of sustainability and notably to address key responsibilities regarding culture.

In this regard, scanty attention has been devoted to cultural sustainability at implementation level, i.e., how general principles or parameters related to this pillar can be pursued through specific actions and practices, so as to demonstrate their contribution to the broader cultural sustainability policy agenda $[29,50]$. Some authors $[16,31,51]$ have started to address-from an organizational perspective-the implementation of cultural sustainability principles at practice level, overcoming the traditional and prevailing focus on other pillars. In this direction, social structures, similarly to the environmental and economic ones, can be pivotal considering that external actors, especially working through partnerships and collaborations, can be involved in implementing specific practices and networks can be exploited to mobilize valuable tangible and intangible resources towards cultural sustainability goals [52].

\subsection{Addressing Cultural Sustainability through Smart Open Innovation: A Conceptual Framework}

Sustainability goals and practices have become particularly relevant in the context of cities as a response to rapid urbanization patterns and urban growth. This trend is clearly signaled by the increasing diffusion of concepts such as the "Green city", the "Eco-city", the "Sustainable city", the "Low-to-Zero Carbon City" and the "Smart city" [3,7,53-56]. In the policy field, a significant push into this direction was given by the 1992 Rio Summit and the formulation of Local Agenda 21 (LA 21), that called for local policy actions oriented at preserving natural resources and the built environment by balancing ecological needs with socio-economic goals of sustainable economies and social justice [54].

Local governments and policy makers have made some effort to include social and intangible themes in the sustainability discourse [5] and academics have recognized the relevance of culture and cultural heritage for city competitiveness, local communities' well-being and economic development $[5,57]$. However, also from the urban development perspective, the main concern still relates to "physical" and "material" issues, like energy efficiency, pollution, urban services and marketing [20,58]. As pointed out by Guzmán et al. [6], all references to culture and cultural heritage in terms of strategy formulation and recommended actions (including the establishment of heritage conservation offices, the attraction of private investments and civic participation in local planning and decision making) are exclusively considered as instrumental to the social, economic and environmental pillars of sustainability $[23,59]$.

The dominant "representation" of culture as "culture for sustainability" [1] in the context of urban sustainable development is particularly evident in the current debate about the smart city $[3,32-34,60]$. Nowadays, smart city is a fuzzy concept and there is no universally agreed upon definition of it. Indeed, different disciplines have emphasized different aspects of the phenomenon [32] and the concept is 
often context-dependent [61]. However, there seems large agreement among researchers, companies, governments and policymakers about the idea that smart cities are ICT-based urban ecosystems aimed at improving economic, social and environmental sustainability $[32,33,62,63]$. This under-appreciation of culture and cultural heritage characterizes both mainstream approaches adopted in smart city literature, i.e., the ICT-oriented approach and the people-oriented approach [61].

The body of research adopting a technology approach emphasizes the use in urban life of ICT and modern technologies (e.g., innovative infrastructures, transport and energy systems, data analytics, etc.) as enablers for initiatives and projects aimed at decreased environmental impacts, economic regeneration, better quality of life, and public and social service enhancement $[37,64,65]$. It is clear that the over-emphasis on physical and material aspects and the hegemony of a "technocratic" approach to urban sustainability lead these studies to attach to culture a marginal role. Smart city projects carried on for cultural heritage preservation and enhancement goals are particularly illustrative of this dynamic, since the focus is on the exploitation of state-of-the-art technologies and applications (e.g., augmented reality, virtual reality, RFID, open data and Internet of Things) for developing new or improved services (i.e., smart innovation) that in turn would contribute to ecological efficiency, economic prosperity and social wellbeing [36,66-69].

Studies belonging to the people-oriented approach highlight, in addition to new technologies, the role of human and social capital in developing new or improved smart city services (i.e., smart innovation) for sustainability goals [32,33,60]. Social capital [70-72] can be defined as "the aggregate of resources embedded within, available through, and derived from the network of relationships possessed by an individual or organization" ([73], p. 151). It is widely regarded as a private and public good able to provide actors with benefits (e.g., preferential access to knowledge, influence, solidarity reputation and new business opportunities) deriving from their memberships in social networks [72,74]. In the context of smart cities, social capital is considered as a key asset for trust and cooperation and it is created and sustained through interaction and exchange among actors being members of open innovation structures $[37,65]$. The people-oriented approach highlights that open innovation [75, 76], being based on networking and inter-institutional relations, seems highly relevant to the new paradigm of the 'smart city' that brings technology, people and places together for the benefit of the citizens and the urban locality $[33,37]$. Smart open innovation models (i.e., open innovation models realized within the context of smart cities) include public-private-people partnerships, living labs and e-governance, which link local government, research institutions, universities, companies, third-sector organizations and citizens into collaborative innovation structures aimed at developing more inclusive, higher quality and efficient services for both visitors and inhabitants [35-38,77,78].

However, as also emerged by the analysis of different projects carried on in smart cities e.g., [60,69] state-of-the-art research has mainly focused on the benefits that smart open innovation can bring to cities in terms of environmental, economic and social sustainability, while ignoring the role that collaborative arrangements (e.g., partnerships) based on multiple stakeholder engagement can play in fostering cultural sustainability goals.

Once recognized, the importance of re-establishing culture as a fourth pillar also within the debate about smart cities, and to understand how collaborative arrangements can be leveraged within smart innovation projects for achieving goals of cultural sustainability, we draw and integrated work by $[29,30]$ and their conceptualization of cultural sustainability with recent knowledge about open innovation in smart cities to build a new framework, as represented in Figure 1. 


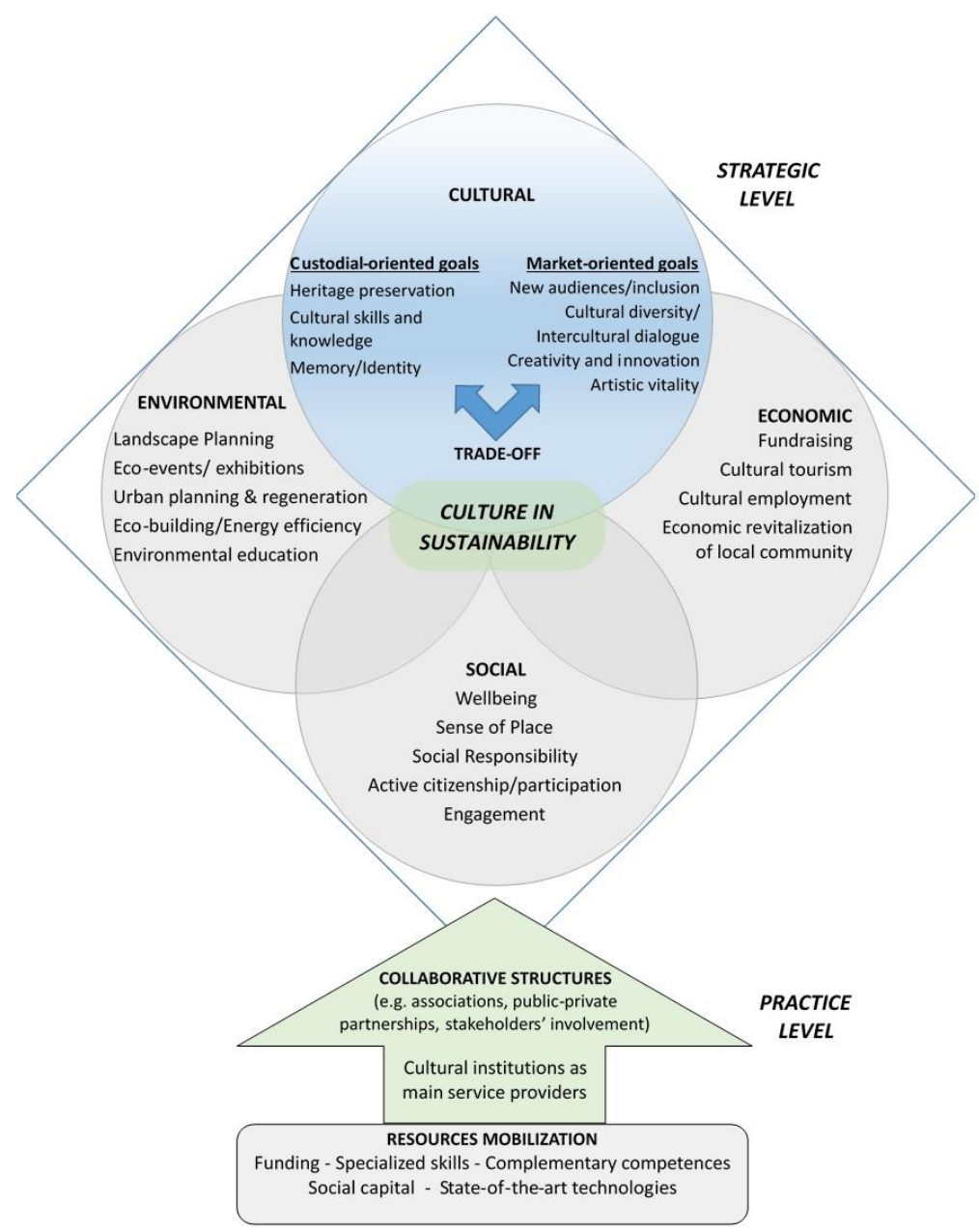

Figure 1. Leveraging Smart Open Innovation for Cultural Sustainability: A Conceptual Framework.

This framework shows how network arrangements based on the collaboration between cultural organizations (i.e., main providers of new services) and a variety of local stakeholders (private firms, non-profit organizations, local governments, citizens, etc.), can be leveraged at (innovation) project level to implement strategies mainly oriented at cultural sustainability goals rather than at environmental, economic and social sustainability. Considering that the development of a new service usually includes the stages of "ideation/design", "implementation/analysis" and "launch and service delivery" [79], we can assume that: In the first stage, actors define what areas of cultural sustainability to address and how the new service to develop will be realized to pursue specific sub-goals; in the subsequent stages of implementation, launch and delivery, specific (tangible and intangible) resources, including funding, specialized skills, complementary competences, social capital and state-of-the-art technologies would be mobilized through collaborative networks to realize specific processes and practices aimed at pursuing the stated goals of cultural sustainability. It is important to highlight that although the framework includes-at the strategic level—all four pillars of sustainability and related areas (represented in Figure 1 as overlapping circles), coherently to Stylianou-Lambert at al. [30], it emphasizes the analytical focus on cultural sustainability (i.e., the related circle is represented through a different color and is put in the foreground). Moreover, within the circle of cultural sustainability, the framework represents the trade-off existing between custodial-oriented goals (e.g., heritage preservation, cultural skills and knowledge, memory and identity) and market-oriented goals (e.g., new audience development, inclusion, cultural diversity, intercultural dialogue, creativity, innovation and artistic vitality). The framework also shows the influence of Loach et al. [29], since in 
this case we focus on the role that—at practice level—social structures (e.g., collaborative arrangements) play in fostering cultural sustainability as designed at the strategic level.

\section{Research Methods}

\subsection{Case Selection}

Relying on the elaborated framework, an exploratory case study analysis [39,40] has been conducted to empirically investigate how the cultural dimension of sustainability has been addressed both strategically and in practice within projects of smart open innovation. On the one hand, the case study analysis would serve to validate the analytical and interpretive potential of the framework. On the other hand, through the example of an innovation project carried out in the context of smart cities, it will provide some useful indications about how to leverage collaboration and multiple stakeholder involvement to pursue strategic goals of cultural sustainability.

In order to answer the research question, we selected an empirical context where the phenomenon of investigation was transparently observable [39]: The development of a complex cultural service system and specifically of a new city museum (MuseoTorino). Indeed, MuseoTorino, conceived as a project of cultural urban heritage preservation and active citizenship, represents a complex service system whose development and maintenance has been realized though the involvement and collaboration of a high number of different city stakeholders, including local public authorities, museums, private organizations, third sector organizations and the local community [80]. Accordingly, such a choice enables us understand to what extant cultural sustainability was, since the beginning, a deliberated and explicit strategic goal of the project and to what extent and how it was pursued in practice through the development and delivery stages by leveraging the open collaborative nature of the new cultural service.

MuseoTorino, whose origins go back to 2004, is a project based on an idea of Daniele Jalla, the executive coordinator of the Museum Services of Turin. It is among the few examples of "smart heritage" [81], a term recently used in the literature to describe a very innovative type of museum that is "ubiquitous", i.e., "it can be enabled, accessed, experienced, and shared by different technologies and communities of users both in person and remotely" and diffused "outside the traditional museum walls and spread around in the whole visitors' experience of a territory" (p.159). The "smartness" of the project was an important criterion guiding our case selection. In this regard, it characterizes the service product, MuseoTorino, for two main reasons: First, from a user's perspective, smartness immediately reflects the most tangible features of the innovative museum that actually consist in a web platform [82]. Secondly, the project has been developed within a formal smart city strategy, undertaken by the city of Turin, who are strongly committed and engaged in the smart development process. Indeed, the development of MuseoTorino was supported by the city context, with local municipalities increasingly devoted to the research of higher quality standards, including new solutions and models for cultural heritage fruition and development, along with the promotion of a new vision of citizens as active users and co-producers of the local cultural system, that is coherently aligned with the image of the "ideal" smart city. For these reasons, MuseoTorino also offers a valuable opportunity to reposition cultural sustainability in the foreground in the recent discourse about smart cities so that it does not need to lag behind the overemphasized dimensions of social, economic and environmental sustainability.

Above all, we chose to focus on MuseoTorino because within the cultural heritage field it can be considered, for all intents and purposes, as an international best practice of innovation, as is shown by a lot of recognitions and awards, including the "Information and Communication Technology 2011 Award", released by the International Council of Museum (ICOM), and the "World Excellence" Award, assigned in 2012 during the event "The Best in Heritage", sponsored by ICOM, ICCROM and UNESCO. Beyond official acknowledgements, the innovative nature of MuseoTorino and its capacity to leverage collaborative arrangements to pursue cultural sustainability goals can also be theoretically grounded 
in innovation studies. In this respect, we refer to both the nature and intensity of change, that make MuseoTorino a complex architectural service innovation [83], and to its high potential for replication, a key requirement to turn any change into innovation, according to a Schumpeterian perspective [84]. More specifically, the uniqueness and originality of MuseoTorino mainly derives from the combination of existing and new elements, including the service concept, the service delivery system, the skills and competencies mobilized to realize it, and the variety of actors involved in its realization. At the same time, its replicability is proved by its capacity to serve as a "service template" to be faithfully utilized in other Italian cities (i.e., Ferrara and Oristano) and to be applied for the realization of similar offerings and value propositions). Indeed, the projects realized in Ferrara and Oristano were based on the same idea inspiring MuseoTorino, sharing the same overall goals, especially in terms of cultural sustainability. MuseoFerrara and MuseOristano were both initiated in partnership with the city of Turin and a number of local public institutions and can be regarded as truly "twin" projects, since they shared a high number of features with the original service product of MuseoTorino, a template for replication in all its constituent dimensions (e.g., service concept, service interface, etc.) and tangible features (notably the website architecture, software, structure, goals and content).

\subsection{Data Collection and Analysis}

Data has been collected combining documents and semi-structured interviews $[40,85]$. Documents used for systematic evaluation as part of the study took a variety of forms, including background papers, brochures, journals, event programs, letters and memoranda, press releases, institutional reports, information available on the museum website and scripts of an intervention at a conference about the project. Above all, we extensively relied on data published on various issues on an online ad hoc journal (Rivista MuseoTorino), containing a lot of information about the museum and related activities and sub-projects. Semi-structured interviews were conducted in the period April-June 2015 with three key-informants: (1) the managing director of the overall "Torino Smart City" program (Key Informant 1-KI1); (2) the project creator and coordinator of the Museum Services of Turin (Key Informant 2-KI2); (3) the director of MuseoTorino (Key Informant 3-KI3). A key feature of the semi-structured interviews is that they provide in-depth information about a certain phenomenon by covering various issue concerning the study. Informants were selected according to a theoretical sampling criterion [86], seeking sampling adequacy rather than sample representativeness. In this respect, we included in the sample participants who had in-depth knowledge of the phenomenon of interest. Two informants (Key Informants 2 and 3) in particular were mainly selected because of their key roles in the realization of the MuseoTorino project; this allowed depth to be achieved and the topic to be interpreted through the meanings that interviewees brought to it. At the same time, since it was important to understand how MuseoTorino was related to the broader smart city strategy realized in Turin and its sustainability goals, we selected another key informant (KI1) directly involved in the formulation of such a strategy and having a deep knowledge about the institutional, economic and social context of the city.

Before carrying on interviews, we analyzed documents to achieve background information and historical insights about the project as well as to identify some additional questions to be asked as part of the research, especially related to change, development and project outcomes [87]. In order to pursue data saturation: (1) Interviews were structured to facilitate asking participants the same questions; (2) we constructed a saturation grid, wherein major issues and topics related to the conceptual framework were listed on the vertical axis and interviews were listed on the horizontal axis [88]; (3) we relied on data triangulation through multiple data sources [85]. Specifically, we did not only use information and insights derived from documents as a valuable addition to our knowledge base but also to verify findings acquired from the interviews. In this respect, it is worth highlighting that gathering data through documents was particularly useful considering that interviews were retrospective in nature and that sometimes informants could have omitted or forgotten some details. 
The integration of documentary data and interviews allowed us to achieve theoretical saturation, that is, adequate knowledge to validate ideas and concepts elaborated in our "meso-level" framework about the role of collaborative structures in pursuing cultural sustainability goals within smart cities. Indeed, through the empirical analysis we mainly aimed at demonstrating the complexity of the phenomenon rather than disentangling such a complexity. Finally, in order to increase the validity and reliability of data, we took notes during interviews and provided the interviews a chance to sum up and clarify the main points they had made [89].

The analysis of empirical data was based on constant comparative analysis or "coding" [90]: Both researchers read through the entire set of data, chunked the data into smaller meaningful parts and then labelled each chunk with a descriptive title (or code) and similar chunks with the same code [91]. Coding was carried out mainly deductively, due to the fact that codes were identified prior to the analysis (as reflected in the conceptual framework) and then looked for in the data. However, we also proceed inductively, considering novel insights emerging from the case study that could be relevant for informing existing knowledge and the framework, especially with regard to the actual implementation process of cultural sustainability-oriented practices and the criticalities that arose during the realization of the projects that- to some extant—created obstacles to the achievement of the stated goals of cultural sustainability.

\section{Findings: Addressing Sustainability throughout the New Museum Development Process}

\subsection{The "Ideation/Design" Stage: The Strategic Goals of Cultural Sustainability}

Referring to the conceptual framework presented in Figure 1, since the design stage of new museum development, the overall innovation strategy assigned a primary role to the cultural dimension, as it is reflected the service concept and the value proposition of MuseoTorino. Indeed, strategic goals of cultural sustainability were not considered as instrumental to other pillars of sustainability, especially the environmental and economic ones. For example, as underlined by a key informant talking about the relationship between the museum and the environment:

Energy savings and $\mathrm{CO}_{2}$ emissions were not relevant within MuseoTorino development strategy [...]. The impacts produced for the environment are not relevant not the least when considering that MuseoTorino exists only as an on-line museum and, consequently, it does not produce the level of consumption, including energy, of a physical museum (KI2).

In a similar way, it was underlined that:

cultural tourism development (e.g., an economic sustainability area, authors' note) was not among the initial objectives of MuseoTorino (KI3).

Faithful to a "culture in sustainability" perspective [1], cultural sustainability goals were viewed as independent objectives to pursue because of the acknowledgment of their relevance for the sustainable development of the museum, although high attention was also put on social sustainability areas, as we will also discuss in more depth:

the improvement of wellbeing and quality of life as well as a higher awareness of citizens about their city were also included among the main goals of MuseoTorino [KI2].

At the strategic level, areas of cultural sustainability were not equally treated since more attention was given to object-oriented goals, clearly reflecting the predominance of a custodial-oriented approach focused on heritage preservation, the transfer of cultural skills and knowledge, and the construction of a public memory and a sense of identity. In this regard, the official mission statement of the museum explicitly points at the preservation of urban heritage (e.g., objects, places, buildings, landscapes) and the transfer of its knowledge as the main goals of the project: 
(the museum's goal is to) preserve, improve, document and communicate knowledge. Its heritage consists of contemporary places and the spaces where it is possible to find, in the form of more or less visible signs, traces and cues, the whole history of the city [92].

However, notwithstanding the main orientation towards traditional areas of cultural sustainability, both goals of heritage preservation and the transfer of knowledge related to the visible and the living city were pursued in an innovative way in comparison to classical civic museums and other cultural institutions like libraries and archives. In this respect, while the mission of traditional museums is to preserve a material collection, MuseoTorino identified itself "with the knowledge that people have about it" [93]. In order to preserve, communicate and extend this knowledge, the new museum was designed as simultaneously real and virtual. In its real dimension, the ambition was to innovate obsolete traditional city and history museums, whose restricted walls made it difficult to communicate the dynamism and growth of modern cities like Turin. Accordingly, it would be a diffused city museum connecting interpretation centers distributed throughout the city, i.e., physical spaces able to stimulate in visitors a process of independent discovery and understanding about the city. In its virtual form, the online museum — to be endowed with an archive, a digital library and media library—would be the main place to guard and communicate the immaterial value of the city and its history. However, compared to archives and libraries, it was intended to promote a dialogue and convergence of intents among different cultural institutions, enhancing the coordination and integration of their activities and reducing conflicts among different disciplines and groups of professionals.

Finally, as for the construction of a public memory and a sense of identity, these cultural sustainability goals were addressed mainly through designing MuseoTorino as a city museum, aimed at disseminating knowledge about its socio-economic structure and the new built urban heritage [94]. Indeed, the building up of a city museum (still missing in Turin at that time) was strongly felt:

for giving an answer also on a cultural level, to the increasing disorientation, a source of estrangement and insecurity, that the big city produces [92],

Effects were exacerbated by the rapid and relentless transformation of Turin and the high level of mobility of its inhabitants. In this respect, as explained by the Mayor of the city:

also the meaning attributed to the process of constructing a public memory is new. Indeed, MuseoTorino aimed at involving all the people who keep and communicate the traces and the evidence of the city history [93].

In the strategic plan of MuseoTorino, all custodial-oriented goals of cultural sustainability (heritage preservation, the transfer of cultural skills and knowledge, the construction of a public memory and a sense of identity) were grounded on the idea to realize a "museum for everyone" [92] or a "participated museum" [92], based on the active involvement, participation and knowledge-sharing of citizens. In this respect, as already said, cultural sustainability goals partially overlapped with and complemented the social sustainability goal of developing a sense of place through active citizenship and engagement. Increasingly emphasized across European cities as a means of producing a sense of place and belonging to the community $[27,95,96]$, active citizenship in political, cultural, social and economic areas of the city life assumed a crucial role for Turin, inhabited both by local natives and immigrants with a high level of geographical mobility. Since it requires in-depth knowledge, understanding and awareness of the city and its identity (i.e., a cultural sustainability goal), this process, in turn, would be sustained by a participative approach, that is:

involving a continuously increasing number of actors, especially all the citizens interested in and available to contribute to the growth of the museum by sharing their knowledge, know-how, memories as well as proposing ideas, initiatives and projects [92]. 
In this direction, MuseoTorino aimed at exercising also a social and civic role by storing and making available information of public value and utility and offering news and reliable data to actively participate in the city life, also contributing to increase the transparency of public administrations and create a dialogue between them and the citizens.

If the adoption of a custodial-oriented approach was undoubtedly prevalent, at least some attention to market-oriented goals was put in the design/ideation stage of the new museum, as is shown by the idea to realize MuseoTorino as a "a museum for everybody" [92], i.e., to develop different audiences beyond the citizens and immigrants who constituted the main public of the new museum. Indeed, MuseoTorino was thought to arouse the curiosity and interest of potential, future or current city visitors by providing them with accurate and diverse knowledge about the historical transformation of Turin, its places, buildings, spaces and events. This would stimulate the museum users to visit the city, enable them to more effectively plan their tours, or explore the city with higher emotional involvement and connection with the city life, i.e.,

feeling as truly natives for all the time they decide to stay in the city [92].

Moreover, the museum was officially designed to satisfy the specific needs of different targets of users, being at the same time

a tool available to the curious and the passionate, to the teacher and the student [92].

\subsection{The "Analysis and Development" Stage: Realizing Cultural Sustainability in Practice}

In this section we will examine to "what extent" and "how" cultural sustainability goals established at the strategic level in the ideation stage were pursued in practice through the complex pilot project of MuseoTorino ("Cantiere MuseoTorino") that started in 2009 and lasted approximately 18 months until the inauguration in March 2011. In particular, guided by our framework (Figure 1), we are interested to explore how specific (tangible and intangible) resources including funding, specialized skills, complementary competences, social capital and state-of-the-art technologies will be mobilized through collaborative arrangements (such as formal partnerships and informal networks) to realize specific processes and practices aimed at addressing the areas of cultural sustainability we previously examined in detail.

MuseoTorino received significant political and financial support; indeed, it was sponsored by public authorities placed at different levels (e.g., the City Municipality, the Province and the Region) while some sub-projects and activities were financed through private funds (e.g., banks). However, interviews reported that sponsorships and opportunities of private funding were not critical factors for carrying on the project since

various partners involved in the different sub-projects and yards had no formal neither informal financial commitment since all the related activities would be realized, as a basic rule, through specific public funding allocated to the overall city museum project (KI3).

However, the case of specific projects financed by private firms demonstrated that the capacity of proposers to communicate convincing ideas was crucial not only to ensure the commitment of private firms to financially support their development but also to help them feel like active agents in the process and sustain the development of social capital among partners. For example, as reported with regard to the digital library project, they received significant financial support from a private bank [97]:

At the basis of the machine there is the trust of the financing body who has recognized an original idea (...). Without this economic fuel nothing would have happened, but (..) in the mechanism of the contract/trust the financing partner did not only have the means. Actually, he has been an active part of the process; the lever and the goal, both together, have led to reinforcing social capital among different parties. 
The founding partnership included a limited number of actors, including, next to the city municipality (the unit responsible for museums and cultural heritage services and serving as initiator and leader of the project), the University of Turin, the Polytechnic, the MIBAC Regional Division, the Piemonte Region and the Province of Turin, which were all informally involved in the early stage of development of the new museum. The working group of the city, beyond a small group of curators coordinated by a head, included collaborators employed in a number of divisions of the city municipality (e.g., archive and document management services, infrastructures and electronic services), that were involved on the basis of their specific competencies and experiences. The curators, in particular, played the main role in the project, taking continued and active participation in the design activities of the museum website as well as coordinating and monitoring the work realized by their collaborators. Moreover, specific proposals or approved projects were respectively submitted to and carried out under the scientific supervision of a Steering Committee.

The mobilization of technical competences and know-how was crucial for the development of MuseoTorino as an online and virtual museum that included a number of service components, notably a library, an electronic journal, geo-referenced city maps and a virtual and permanent exhibition. To this end, a formal partnership was signed with a young IT firm who was specialized in web development services and the application of highly innovative technologies. Beyond providing technical expertise, the start-up also coordinated, together with Jalla's team of professionals, the many activities required to collect and integrate the contents of the museum website, such as historical investigations, the search and collection of documents, the compilation and editing of tabs related to places and people, the production and re-production of images, the elaboration of the relevant mapping, the update of the archaeological map of the city, and the digitalization of books and texts.

The selection of specific partners (firms, associations, individuals) involved in the pilot project was an easy, spontaneous and informal endeavor. Indeed, they were chosen on the basis of previous experiences of work collaboration with the city municipality and the creator, who already knew them for their competences, reputation and trustworthiness; at the same time, the building of the collaborative network benefited from a favorable local context oriented at openness and networking:

each partner had previous experience of cooperation and there was a reciprocal acknowledgement of competences...there had been a convergence of factors related, among others, to the research interests of universities, the Municipality's willingness to sustain the smart development of the city, and the diffusion of initiatives and instruments that were able to encourage partnerships' formation and networking activities (KI3).

To carry on the overall master plan of the project, there was the adoption of an incremental management approach based on the realization of a number of research projects called "yards" ("cantieri"), each focusing on a specific area or theme. The experimental stage was based on 19 yards and involved about 80 people, including freelancers, volunteers or members of the city municipality, local districts, research and protection entities, museums, archives, libraries, cultural institutions and associations. These actors, selected because of their consolidated experience in activities of study and research about the history of the city and in the preservation, enhancement or promotion of the urban cultural heritage, contributed to the production of texts, graphics, photos for mapping the city and of a significant number of "catalogue tabs", focused on the description of various places, events, actors and books related to Turin.

Each yard is associated to a working group. Each is created according to specific competences required to pursue the goal of the sub-project [ ... . . It is the Scientific Committee that decides in which yard to invest and which to support (KI2).

Among the various yards, the development of the digital library is a highly illustrative example of the importance assumed by "a federative model" [97], i.e., a collaborative-oriented and inclusive 
approach that inspired the project and characterized it throughout its temporal unfolding. Indeed, in view of adopting this federative model, the initial idea to outsource the project to a specialized firm was abandoned and replaced by the establishment of multiple formal partnerships with a number of partners, e.g., the public research institute IRES Piemonte, the University of Turin and most libraries in the city. All these actors worked together, putting their human and material resources and technical competences together to realize a complex digitalization process that lead to 150 digital texts in just two months. As explained by the director of IRES documentation center and commercial office:

the adjective "federal" evokes the right ideas since it tries to describe the most innovative and stimulating managerial aspects that characterize a dynamic and changeable entity (i.e., MuseoTorino); in a federation there is a pact stipulated among actors who preserve their autonomy and who, consequently, join together because they share a common goal, by providing the specific inputs that they own [97].

More generally, as underlined by KI3:

At partnership level, there was a process of cross-fertilization among different partners that had led to an increase in the knowledge and social capital of partners owned with complementary resources and competences (KI3).

Material resources (funds, physical infrastructures and technologies) along with technical and professional competences of many city stakeholders, were mobilized through network structures and their wide involvement in specific yards not simply to pursue the cultural sustainability goals of preserving urban heritage and transferring knowledge and cultural skills, but also to foster-through their active commitment in the study of the city transformation process-the development of a sense of place and belonging. At the same time, assigning the preservation of urban heritage and the transfer of cultural knowledge to city stakeholders and citizens could not be done without guaranteeing the authenticity and reliability of this knowledge for the museum future users. For these reasons, the bottom-up and participatory logic was combined with a formal centralized governance: The Scientific Committee was responsible to select which yards to activate and support, to analyze and critically examine the knowledge produced by local actors involved in each yard, who were open to collectively discuss contents as well as inclined to potential revisions and improvement of contents. This means that:

although each yard constituted a distinct and independent working group based on distinctive competences, all the key decisions were centralized in the leading partner (the city municipality, authors' note) (KI2).

As it happened in a number of smart open innovation projects carried out in other cities, also in the case of MuseoTorino, state-of-the-art technologies, including semantic web, open data and a new generation database, were exploited in the experimentation stage to realize what had been designed at the strategic level as a "museum for everyone" [92] as well as to foster user innovation, two people-oriented cultural sustainability goals. In this respect, a large variety of forms of knowledge resources related to the urban heritage were collected, put together and organized within the website to satisfy the needs and expectations of different audiences, including scholars, researchers, students, people passionate about urban heritage and tourists in search of information for planning their tour in the city. The innovative website architecture and the advanced technological platforms, standards and applications offered many opportunities for customizing the ways for searching for information on the website and experiencing the museum visit. Notably, through a Google Map application, potential visitors could navigate the site in a highly interactive way and identify the exact physical position in the city of historical buildings, libraries, museums and, by freely exploring the map, could get access for each object notes, links to archives and libraries, and complementary sources. 
Innovative technologies were also used to make MuseoTorino a "web portal" [92], enabling the search and access to complementary sources of knowledge about the city available elsewhere in the web. Finally, the implementation of an open data model would enable the sharing of information with users and other systems (e.g., social networks) while the adoption of a license scheme served to facilitate the free use of the website contents by potential developers and innovators.

\subsection{The "Launch and Delivery" Stage: Reinforcing Cultural Sustainability-Oriented Practices}

The last stage of the project, i.e., its "launch and delivery", was initiated in March 2011, when the Museum opened its doors to the public with the official launch of the website and the public screening of a multimedia performance about the history of the city. At that time, a number of service components still required to be developed, old projects needed to be completed and new projects to be initiated. Actually, there was a deliberate intention to offer visitors an incomplete website so as to transmit the message that activities aimed at sustaining the cultural sustainability goals of preserving urban cultural heritage, transferring skills and knowledge, and constructing and reinforcing a strong sense of place and identity, constituted an endless task for all citizens.

Given the changeable and process nature of the museum, social structures-based on formal partnerships and citizens' involvement-were reinforced after the launch. Interestingly, in this stage, practices adopted to mobilize tangible and intangible resources through collaborative arrangements were revealed to be helpful not only in relation to conservation-oriented goals of cultural sustainability, but also to develop new audiences and foster creativity and innovation. Firstly, there was a clear commitment to strengthen the intensity of the collaboration initiated in an informal way with actors working in the project and specific yards:

[nowadays] all working relations within each yard have been formalized. In an overall unifying perspective, they assume the form of peer-to-peer relationships [ ... ]. The city municipality puts itself at the center of relationships among partners (KI3).

As we understood, especially looking at extant website documentation, this was done by realizing a formal scheme of memorandum of understanding and bilateral agreements to be subscribed by two parties: the city municipality and the founding partners and actors working on the project. The adoption of the memorandum, that has to be renewed on an annual basis, has become an institutionalized practice also for new projects (and new partners) activated after the launch. This decision was mainly motivated by the highly innovative content of specific projects that would have benefitted from more structure and formalization, for example, in terms of establishing and sharing milestones and monitoring points among partners. All the agreements contained precise and detailed information about the content of the partnership, clarifying the specific goals and modes of collaboration and highlighting the reciprocal commitment of each party in realizing the specific sub-project (including "yards"), making available their know-how and competences, forming ad hoc working groups and even planning conjoint activities to promote the involvement of other potential actors.

Secondly, there was an effort to enlarge the collaborative network revolving around the realization of MuseoTorino. Indeed, while in the development stage, the selection and involvement of partners was mainly based on previous relations and experiences of collaboration; the future development of MuseoTorino will more significantly rely on "the engagement of unlimited and undifferentiated users" (KI3),

As it has also been clearly explained by the councilman:

From the commitment to the city-user it has drawn an impulse to go further in the perspective to assign to the citizens the role of protagonists and not only that of recipients of museum policies. This by allowing them to become, to different degrees and levels of involvement, agents of the work of protection and enhancement of the cultural heritage [98]. 
A relevant step in this direction was made through the implementation-for the website-of an approach based on user-generated contents and inspired to the "Wikipedia" logic through which MuseoTorino aimed at stimulating the participation of citizens in sharing their knowledge and experiences, proposing ideas and projects. More specifically, the website was made more interactive and it was possible for the web user community to create new contents and modify the existing ones, but also to signal mistakes or omissions. Moreover, the web architecture was configured in order to enable a valuable interaction with users, facilitating their involvement: All online visitors could potentially express their will to participate in new projects and activities oriented at the development and growth of MuseoTorino; this could be done by identifying new potential research yards to activate, suggesting new fields of investigation and ideas to enrich its collection, proposing integrative materials and new touristic trails, compiling specific tabs, sharing stories, memories and knowledge about the city and its history.

Once again, however, the exploitation of open social structures for cultural sustainability had to be balanced with the need of ensuring the quality of the overall collective and participatory process of co-creating the museum reinforcing MuseoTorino's commitment towards maintaining a high reputation and trustworthiness among citizens and visitors; this was done by innovating the specific way in which the "Wikipedia" logic was implemented: Before their definitive online publication, user-generated contents were filtered and validated by MuseoTorino's technical team, who was fully responsible to verify the reliability, accuracy and validity of all information. In a similar way, suggested research projects to activate always required the preliminary technical evaluation and approval by the scientific committee to be initiated.

\section{Discussion and Conclusions}

The overall goal of this paper is to deepen our knowledge about the strategic role of cultural sustainability for cultural institutions and cultural policymakers, and to identify some practices that could be adopted to address cultural sustainability through the collaborative development of new service offerings. To address this research issue we chose smart cities and the development of new smart city services as the privileged context of both conceptual development and empirical investigation. Indeed, the need to restore cultural sustainability in comparison to other pillars of sustainability has been emphasized in the recent smart city discourse; at the same time, increasing importance has been acknowledged to open innovation models and the collaborative development of new smart city services.

To this end, we embraced a "culture in sustainability" perspective [1] to firstly elaborate a new framework linking together the strategic level and the implementation level in addressing cultural sustainability goals in the context of smart open innovation. The framework shows how a cultural sustainability strategy, established in the design stage of new service development, can be implemented through mobilizing tangible and intangible resources within collaborative structures (e.g., partnership, associations, stakeholders' involvement). Relying on the elaborated framework, we carried on an exploratory case study of an innovation project oriented at the development of a new city museum in the context of an Italian smart city (Turin).

Empirical results provided evidence of the analytical value of the framework with regard to the role of collaborative structures (e.g., partnerships, informal arrangements, user involvement) to address cultural sustainability goals through the development of new smart city services. Specifically, the case study showed how the frameworks respectively proposed by Loach et al [29] and Stylianou-Lambert et al. [30] can be combined together (Figure 1) to fill a relevant research gap, i.e., to understand how cultural sustainability can be first strategically designed and then realized in practice at the project level, throughout the different stages of development of a new cultural service offering; that is from the ideation phase to the launch and delivery phase of a new service (i.e., a new city museum). The framework allows us to understand the meaning and value of a "culture in sustainability" perspective [1] according to which cultural sustainability is regarded not as secondary 
in comparison to environmental, economic and social pillars but as independent and equally important, in line with what many authors have recently pointed out [11,19]. At the strategic level, the analysis of a complex multi-stakeholder innovation project helped us to put in the foreground the complex role played by cultural institutions, like museums and libraries, that risks to be underappreciated with an over-emphasis on the triple bottom line approach $[95,99]$. Cultural sustainability goals, indeed, were clearly reflected —at the strategic level—in the service concept and value proposition of MuseoTorino, while other pillars, notably environmental and economic, were not expressly included in the strategy plan of the project. In addition, social sustainability, mainly in terms of sense of identity and active citizenship, was also a targeted pillar of the project, although it was considered as complementary and, anyway, as not more important than culture itself. These findings supported the statement that a clear distinction or even a marked contrast among sustainability pillars is not always possible nor useful [30]. In this case, in particular, social and cultural sustainability parameters were closely related and mutually reinforcing, both to be pursued through a participated approach, that also included decision-making processes about the city and a collective action of care and protection of the urban heritage.

Assuming a more critical perspective, notwithstanding the importance to restore the value of culture in the sustainability debate, in the context of smart city strategies a disproportionate or even exclusive attention focus on cultural sustainability can be justified and is acceptable only for a limited number of smart city projects (such as MuseoTorino) within the overall portfolio of initiatives and activities. Otherwise, there is the risk of failing to address the overall mission of any smart development strategy that, indeed, should simultaneously consider all the pillars of sustainability, pursuing environmental saving and energy efficiency along with pushing local economies and ensuring better social services and quality of life to citizens and the local community $[3,33,61]$. This actually happened for Turin, where the formal smart development program was based on

Public-private partnerships including 160 actors and 66 different city stakeholders "called to" work together around a number of different thematic tables including, among others, energy, mobility, health, life, inclusion and culture (KI1).

This means that taking the illustrative example of environmental sustainability, the adoption of innovative technologies to make physical museums, libraries and archives more efficient and environmentally-friendly should be included in any smart development plan, independently of their primary role as cultural institutions devoted to the preservation of cultural heritage and the transfer of cultural knowledge and skills to present and future generations. In a similar way, smart technologies and collaborative structures should be leveraged to make cultural institutions part of an innovation ecosystem able to promote local economies, creating new jobs and sustaining cultural tourism. In this respect, however, MuseoTorino was not completely successful, as demonstrated by the words used by KI3 with regard to the impact produced by the project at the economic level:

[... ] Economic impact was circumscribed and derived from few projects. Notably, in the digitalization project we could take advantage of a funding opportunity from Compagnia San Paolo (an Italian bank, authors' note) that made available to workers who had been receiving lay-off benefits training and supplementary income vouchers.

In a similar way, KI2 claims:

The lack of funding has tremendously diminished the potential of the project. The economic impact was not relevant considering that it led to the enrollment of only eight scientific professionals in the period 2010-2011

Similarly, the capacity of MuseoTorino to promote cultural tourism was very low:

The website is visited only by foreign experts but it is not appealing to tourists (KI3). 
We can conclude that the implementation of a "subsidiary model" (that also was a target goal of MuseoTorino) was not completely successful and that fundraising campaigns, highly emphasized in the context of smart cities to address economic sustainability [100], were not planned or probably resulted ineffective in sustaining the overall project.

Beyond clarifying the meaning of a "culture in sustainability" perspective in the context of smart open innovation, the empirical analysis of MuseoTorino also helps to reveal how in developing new smart services, cultural institutions are called to manage the classical trade-off between a custodial-orientation focused on urban heritage (e.g., an "object-based" approach) and a market-orientation approach focused on visitors, their needs and expectations (e.g., a "people-oriented" approach) [44-48]. Currently, there is still a paucity of empirical studies about how tensions between these two orientations are managed to implement cultural sustainability strategies (for an exception see [30]). In the case of MuseoTorino, it is interesting emphasizing that although the predominance of a custodial-oriented approach focused on heritage preservation, the transfer of cultural skills and knowledge, the construction of a public memory and a sense of identity, a viable pathway is pursuing custodial-oriented goals in an innovative manner compared to traditional cultural institutions (museums, libraries, archives, etc.). In this respect, it emerged that MuseoTorino differentiated from both traditional civic museums and city museums. Compared to the former, the main novelty was its combined-real and virtual—nature and the balanced integration of different channels, notably interpretation centers and the museum website, and related material and immaterial elements to pursue its institutional mission. MuseoTorino also distinguished itself from most city museums in the effort to construct a public memory and a sense of identity, mainly relying on a planned participatory approach, i.e., citizens' active involvement, participation and knowledge sharing in both the development and delivery of the new service system. Indeed, this channel was also able to promote to some extent some market-oriented goals, e.g., inclusion and new audience development along with collective creativity and innovation.

The case study analysis also contributes to fill a relevant research gap, since it provides new knowledge about how cultural sustainability can been implemented in practice through the development of smart open innovation projects by leveraging social structures for innovation (i.e., formal partnerships, informal arrangements, citizens' involvement). In this respect, only very recently, [29] pointed out the need to identify practices and processes to be adopted to pursue goals of cultural sustainability that would support cultural institutions in making their implementation effort more effective. Through analyzing the stages of development, launch and delivery of a smart open innovation project, the case study provides valuable knowledge about how some organizational practices and processes can serve to mobilize tangible and intangible resources, including funding, specialized skills, complementary competences and innovative technologies through multi-stakeholder partnerships and citizens' involvement. In this direction, it can provide not only valuable indications to cultural institutions committed to new service development and smart innovation but also useful insights to local policy makers working in the formulation of smart city development policies oriented at cultural sustainability goals. The case study showed that a relevant practice is the initial selection of a limited number of partners to be involved in the project, whose choice is based on previous relationships, and thus on their trust, reputation and recognized competences. This choice is viewed as particularly important to address the cultural sustainability areas of heritage preservation and transfer of knowledge about the city. Indeed, these activities require specialized competences and the work of professionals, scholars and researchers actively committed as experts to culture and activities related to urban heritage. However, specialized competences in the cultural heritage field have to be combined with knowledge and technical expertise in state-of-the-art technologies and applications. As it has been emphasized in the smart city debate and empirically documented in many smart cities worldwide [34,101,102], technological innovation is crucial in the development of new city services: In the case of MuseoTorino, the partnership with an IT start-up was not only instrumental to the realization of the website and its complex architecture but also for the development of some 
smartphone applications based on data and information available on the museum website. Finally, technology also allowed the implementation of a "Wikipedia logic" that would serve as a tool for user involvement in the endless development of MuseoTorino.

The careful analysis of the implementation and delivery stages allowed us to identity a relevant organizational practice used to manage the tension existing between two needs. On the one hand, MuseoTorino had to maintain high reputation and trustworthiness about the quality of heritage preservation and transferred knowledge; this would inevitably have led to maintain a "low inclusive" approach over time. On the other hand, it aimed at sustaining the development and maintenance of a public memory and a sense of identity together with active citizenship, that necessarily required high inclusion and participation. The answer to manage this tension was the adoption of a dual mode of governance based on the combination of a bottom-up and a top-down logic: (1) An incremental approach of different sub-projects (e.g., based on yards and a Wikipedia logic) with an "open" nature so that everyone could propose a specific yard or contribute to enrich the website with new tabs and information about the city; (2) the setup of a Scientific Committee who critically evaluated and decided which yards to activate and was responsible for the approval of any content proposed by undiversified and unlimited users.

Unfortunately, we do not have enough data to evaluate the actual degree of effectiveness of this practice, since we cannot exclude the possibility that some groups or organizations could have felt excluded or passed by in the process. This means that we cannot evaluate to what extant MuseoTorino achieved the stated goals to be realized as a truly "participatory museum". Neither can we document the broader social impact produced by the development of the new museum. Indeed, as reported by KI2 at the time of the interview:

We have not realized any study or research to evaluate the social impact of MuseoTorino. Consequently, we cannot quantify in any way the impact of MuseoTorino in terms of the improvement of life quality and awareness of Turin citizens, that were key objectives of the project.

In a similar way, since information on this website is available only in the Italian language, we can infer that this can be a serious impediment both to the ambition to make MuseoTorino a "museum for everyone" as well as to the chance to attract foreign tourists and boost cultural tourism in Turin.

Anyway, however, we are in the position to claim that MuseoTorino has likely contributed to the transfer and diffuse of knowledge about the city and its history given the high number of people who visited the website:

There have been 622.570 visits on the website and 424.826 single visitors, since the launch of the website (on 17 March 2011) to the 31st December 2013, with a high percentage of access from other sites, also thanks to the semantic structure of the website that enables its high position within search engines (especially Google) (KI2).

The present study has some limitations. Firstly, it is based only on three interviews; however, extensive document analysis has been used for both data and theoretical saturation. If we can admit that this number can be enough to show the complexity of the issue under investigation (and, in particular, the analytical and interpretive value of our framework), it is not certainly able to disentangle such a complexity that actually remained "black-boxed" to a significant extent. To open up the process and provide an in-depth analysis of practices and processes adopted to implement cultural sustainability in practice an in-depth analysis of the development project of MuseoTorino is required. This more ambitious goal, in turn, would be necessarily based on collecting data through a significant and representative number of interviews and the inclusion of many subjective understandings and interpretations of the phenomenon. To this end it would be valuable to interview other actors involved in the projects, such as artists, volunteers and representatives of organizations involved in the various yards active along the innovation process. Moreover, it would also be very 
useful to survey residents of Turin as well as visitors of the website to evaluate their actual degree of involvement in the project and their overall degree of satisfaction about it.

A second limitation derives from the retrospective nature of the data collected through interviews and the lack of real time data on the development process of the museum. Focusing on specific smart open innovation projects, future studies could adopt a longitudinal approach, looking at how specific practices and processes oriented at cultural sustainability goals emerge and unfold over time throughout the various stages of new smart city service development.

Author Contributions: L.E. carried out paragraphs: Section 2.2 Addressing cultural sustainability through smart open innovation: a conceptual framework; Section 4.2 The "analysis and development" stage: realizing cultural sustainability in practice; Section 4.3 The "launch and delivery" stage: reinforcing cultural sustainability-oriented practices. R.M. carried out the paragraphs: Section 2.1 The surge of "culture" in the sustainability debate: moving towards strategy in practice; Section 4.1 The "ideation/design" stage: the strategic goals of cultural sustainability. Both the authors carried out the Abstract, the Introduction and the paragraphs: Section 3 Research Methods; and, Section 5 Discussion and conclusions. All authors read and approved the final manuscript.

Acknowledgments: The authors wish to acknowledge the support offered especially by Daniele Jalla, coordinator of museum services of MuseoTorino, in the process of data collection.

Conflicts of Interest: The authors declare no conflict of interest.

\section{References}

1. Soini, K.; Dessein, J. Culture-Sustainability Relation: Towards a Conceptual Framework. Sustainability 2016, 8, 167. [CrossRef]

2. Stylianou-Lambert, T.; Boukas, N.; Bounia, A. Politics, tourism and cultural sustainability. In Theory and Practice in Heritage and Sustainability: Between Past and Future; Auclair, E., Fairclough, G., Eds.; Routledge: London, UK, 2015; p. 176.

3. Haarstad, H. Constructing the sustainable city: Examining the role of sustainability in the 'smart city'discourse. J. Environ. Policy Plan. 2017, 19, 423-437. [CrossRef]

4. Dumitrescu, C. Culture, sustainable urban development and urban regeneration. Rev. Econ. 2014, 66, 23-38.

5. Gražulevičiūtè, I. Cultural Heritage in the Context of Sustainable Development. Environ. Res. Eng. Manag. 2006, 37, 74-79.

6. Guzmán, P.C.; Roders, A.P.; Colenbrander, B.J.F. Measuring links between cultural heritage management and sustainable urban development: An overview of global monitoring tools. Cities 2017, 60, 192-201. [CrossRef]

7. Vojnovic, I. Urban sustainability: Research, politics, policy and practice. Cities 2014, 41, S30-S44. [CrossRef]

8. Opoku, A. The role of culture in a sustainable built environment. In Sustainable Operations Management. Measuing Operations Performance; Charini, A., Ed.; Springer International Publishing: Cham, Switzerland, 2015; pp. 37-52.

9. Wu, S.R.; Fan, P.; Chen, J. Incorporating culture into sustainable development: A cultural sustainability index framework for green buildings. Sustain. Dev. 2016, 24, 64-76. [CrossRef]

10. Pascual, J. Culture and Sustainable Development: Examples of Institutional Innovation and Proposal of a New Cultural Policy Profile. Barcelona: Committee on Culture of United Cities and Local Governments. 2009. Available online: http:/ / www.agenda21culture.net/index.php/fa/docman/agenda21/241-report4full/file (accessed on 19 May 2016).

11. Pascual, J. Culture as a pillar in sustainability: The best is yet to come. Economia della Cultura 2016, 26, 557-572.

12. Sacco, P.L.; Blessi, G.T.; Nuccio, M. Cultural policies and local planning strategies: What is the role of culture in local sustainable development? J. Arts Manag. Law Soc. 2009, 39, 45-64. [CrossRef]

13. Cities, United, and Local Governments. Agenda 21 for Culture; Committee on Culture-United Cities and Local Governments: Barcelona, Spain, 2004.

14. Duxbury, N.; Jeannotte, M.S. Making it real: Measures of culture in local sustainability planning and implementation. In Making Culture Count. New Directions in Cultural Policy Research; MacDowall, L., Badham, M., Blomkamp, E., Dunphy, K., Eds.; Palgrave Macmillan: London, UK, 2015; pp. 145-161. 
15. Duxbury, N.; Cullen, C.; Pascual, J. Cities, culture and sustainable development. In Cultures and Globalization: Cities, Cultural Policy and Governance; Anheier, H.K., Isar, Y.R., Eds.; Sage: Thousand Oaks, CA, USA, 2012; pp. 73-86.

16. Pop, I.L.; Borza, A. Factors Influencing Museum Sustainability and Indicators for Museum Sustainability Measurement. Sustainability 2016, 8, 101. [CrossRef]

17. Holden, E.; Linnerud, K.; Banister, D. Sustainable development: Our common future revisited. Glob. Environ. Chang. 2014, 26, 130-139. [CrossRef]

18. Holden, E.; Linnerud, K.; Banister, D. The imperatives of sustainable development. Sustain. Dev. 2017, 25, 213-226. [CrossRef]

19. Hawkes, J. The Fourth Pillar of Sustainability: Culture's Essential Role in Public Planning; Common Ground: Champaign, IL, USA, 2001.

20. Rana, R.; Piracha, A. Cultural frameworks. In Urban Crisis: Culture and the Sustainability of Cities; United Nations University Press: Tokyo, Japan, 2007.

21. Elkington, J. Cannibals with Forks: The Triple Bottom Line of 21st Century; Alternatives Journal: Waterloo, Belgium, 1997; Volume 73.

22. Kajikawa, Y. Research core and framework of sustainability science. Sustain. Sci. 2008, 3, 215-239. [CrossRef]

23. Boström, M. A missing pillar? Challenges in theorizing and practicing social sustainability: Introduction to the special issue. Sustain. Sci. Pract. Policy 2012, 8, 3-14. [CrossRef]

24. Throsby, D. Sustainability and culture some theoretical issues. Int. J. Cult. Policy 1997, 4, 7-19. [CrossRef]

25. Throsby, D. 22 Cultural Sustainability. In A Handbook of Cultural Economics; Edward Elgar Publishing: Zottery, UK, 2003; Volume 183.

26. Throsby, D. Linking Cultural and Ecological Sustainability. Int. J. Divers. Organ. Commun. Nations 2008, 8, 15-20. [CrossRef]

27. Dunphy, K. Making Culture Count: The Politics of Cultural Measurement; Palgrave Macmillan: Reino Unido, UK, 2015; pp. 145-161.

28. Duxbury, N.; Kangas, A.; De Beukelaer, C. Cultural policies for sustainable development: Four strategic paths. Int. J. Cult. Policy 2017, 23, 214-230.

29. Loach, K.; Rowley, J.; Griffiths, J. Cultural sustainability as a strategy for the survival of museums and libraries. Int. J. Cult. Policy 2017, 23, 186-198. [CrossRef]

30. Stylianou-Lambert, T.; Boukas, N.; Christodoulou-Yerali, M. Museums and cultural sustainability: Stakeholders, forces, and cultural policies. Int. J. Cult. Policy 2014, 20, 566-587. [CrossRef]

31. Wickham, M.; Lehman, K. Communicating sustainability priorities in the museum sector. J. Sustain. Tour. 2015, 23, 1011-1028. [CrossRef]

32. Hollands, R.G. Will the real smart city please stand up? Intelligent, progressive or entrepreneurial? City 2008, 12, 303-320. [CrossRef]

33. Nam, T.; Pardo, T.A. Conceptualizing smart city with dimensions of technology, people, and institutions. In Proceedings of the 12th Annual International Digital Government Research Conference: Digital Government Innovation in Challenging Times, College Park, MD, USA, 12-15 June 2011; pp. 282-291.

34. Komninos, N.; Pallot, M.; Schaffers, H. Issue on Smart Cities and the Future Internet in Europe. J. Knowl. Econ. 2013, 4, 119-134. [CrossRef]

35. Errichiello, L.; Marasco, A. Open service innovation in smart cities: A framework for exploring innovation networks in the development of new city services. Adv. Eng. Forum 2014, 11, 115-124. [CrossRef]

36. Marasco, A.; Errichiello, L. The role of networking in the development of new city services. A framework for exploring smart public-private service innovation networks. Eur. Rev. Serv. Econ. Manag. 2016, 1, 65-100.

37. Paskaleva, K.A. The smart city: A nexus for open innovation? Intell. Build. Int. 2011, 3, 153-171. [CrossRef]

38. Schaffers, H.; Komninos, N.; Pallot, M.; Trousse, B.; Nilsson, M.; Oliveira, A. Smart Cities and the Future Internet: Towards Cooperation Frameworks for Open Innovation. In The Future Internet-Future Internet Assembly: Achievements and Technological Promises; Domingue, J., Ed.; Springer: Berlin, Germany, 2011; pp. 431-436.

39. Eisenhardt, K.M. Building theories from case study research. Acad. Manag. Rev. 1989, 14, 532-550. [CrossRef]

40. Yin, R.K. Case Study Research: Design and Methods; Sage Publications: Thousand Oaks, CA, USA, 2013.

41. Soini, K.; Birkeland, I. Exploring the scientific discourse on cultural sustainability. Geoforum 2014, 51, $213-223$. [CrossRef] 
42. Duxbury, N.; Gillette, E. Culture as a Key Dimension of Sustainability. Exploring Concepts, Themes and Models. 2007. Available online: www.cultureandcommunities.ca/downloads/WP1-CultureSustainability.pdf (accessed on 25 January 2018).

43. Di Pietro, L.; Guglielmetti Mugion, R.; Renzi, M.F.; Toni, M. An audience-centric approach for museums sustainability. Sustainability 2014, 6, 5745-5762. [CrossRef]

44. Gilmore, A.; Rentschler, R. Changes in museum management: A custodial or marketing emphasis? J. Manag. Dev. 2002, 21, 745-760. [CrossRef]

45. Kotler, N.; Kotler, P. Can museums be all things to all people?: Missions, goals, and marketing's role. Mus. Manag. Curatorship 2000, 18, 271-287. [CrossRef]

46. Camarero, C.; Garrido, M.J. Improving museums' performance through custodial, sales, and customer orientations. Nonprofit Volunt. Sect. Q. 2009, 38, 846-868. [CrossRef]

47. Camarero, C.; Garrido, M.J. Fostering innovation in cultural contexts: Market orientation, service orientation, and innovations in museums. J. Serv. Res. 2012, 15, 39-58. [CrossRef]

48. Tobelem, J.M. The marketing approach in museums. Mus. Manag. Curatorship 1997, 16, 337-354. [CrossRef]

49. Goulding, C. The museum environment and the visitor experience. Eur. J. Market. 2000, 34, $261-278$. [CrossRef]

50. Evans, B.; Theobald, K. Policy and practice LASALA: Evaluating local agenda 21 in Europe. J. Environ. Plan. Manag. 2003, 46, 781-794. [CrossRef]

51. Adam, R. Missing the 2010 biodiversity target: A wake-up call for the convention on biodiversity. Colo. J. Int'l Envtl. L. Pol'y 2010, 21, 123.

52. Bevilacqua, C.; Esposito, G.; Trillo, C. Evaluation of PPP Performance: A Comparative Analysis of 12 Case Studies in the Boston Metropolitan Area, CLUDs Project First Scientific Report, Economic Development Strategies-The Role of Public Private Partnership; 2012. Marie Curie Actions People International Research Staff Exchange Scheme Project N. 269142—CLUDs-Commercial Local Urban District Programme.

53. Camagni, R.; Capello, R.; Nijkamp, P. Towards sustainable city policy: An economy-environment technology nexus. Ecol. Econ. 1998, 24, 103-118. [CrossRef]

54. Evans, B.; Joas, M.; Sundback, S.; Theobald, K. Governing Sustainable Cities; Taylor \& Francis: Abingdon, UK, 2013.

55. Finco, A.; Nijkamp, P. Towards a sustainable future of cities in Europe: An evaluation of sustainable city initiaties using multicriteria decision support methods. In Land Use Simulation for Europe; Stillwell, J., Scholten, H.J., Eds.; Springer Science \& Business Media: Berlin, Germany, 2001; Volume 63, pp. 173-192.

56. Khan, S.; Zaman, A.U. Future cities: Conceptualizing the future based on a critical examination of existing notions of cities. Cities 2018, 72, 217-225. [CrossRef]

57. Tweed, C.; Sutherland, M. Built cultural heritage and sustainable urban development. Landsc. Urban Plan. 2007, 83, 62-69. [CrossRef]

58. Shirazi, M.R. Sustainability and the Hegemony of Technique. Towards a new approach to cultural sustainability. In Proceedings of the Inter-Disciplinary. net 10th Global Conference: Environmental Justice and Global Citizenship, Mansfield College, Oxford, UK, 8-10 July 2011.

59. Shmeleva, S.E.; Shmeleva, I.A. Sustainable cities: Problems of integrated interdisciplinary research. Int. J. Sustain. Dev. 2009, 12, 4-23. [CrossRef]

60. Caragliu, A.; Del Bo, C.; Nijkamp, P. Smart cities in Europe. J. Urban Technol. 2011, 18, 65-82. [CrossRef]

61. Bibri, S.E.; Krogstie, J. Smart sustainable cities of the future: An extensive interdisciplinary literature review. Sustain. Cities Soc. 2017, 31, 183-212. [CrossRef]

62. Neirotti, P.; De Marco, A.; Cagliano, A.C.; Mangano, G.; Scorrano, F. Current trends in Smart City initiatives: Some stylised facts. Cities 2014, 38, 25-36. [CrossRef]

63. Pierce, P.; Ricciardi, F.; Zardini, A. Smart Cities as Organizational Fields: A Framework for Mapping Sustainability-Enabling Configurations. Sustainability 2017, 9, 1506. [CrossRef]

64. Marsal-Llacuna, M.L.; Colomer-Llinàs, J.; Meléndez-Frigola, J. Lessons in urban monitoring taken from sustainable and livable cities to better address the Smart Cities initiative. Technol. Forecast. Soc. Chang. 2015, 90, 611-622. [CrossRef]

65. Paskaleva, K.; Evans, J.; Martin, C.; Linjordet, T.; Yang, D.; Karvonen, A. Data governance in the sustainable smart city. In Informatics; Multidisciplinary Digital Publishing Institute: Basel, Switzerland, 2017; Volume 4, p. 41. 
66. Buonincontri, P.; Micera, R. The experience co-creation in smart tourism destinations: A multiple case analysis of European destinations. Inf. Technol. Tour. 2016, 16, 285-315. [CrossRef]

67. Della Corte, V.; Aria, M.; Del Gaudio, G. Smart, open, user innovation and competitive advantage: A model for museums and heritage sites. Mus. Manag. Curatorship 2017, 32, 50-79. [CrossRef]

68. Pallot, M.; Trousse, B.; Senach, B.; Schaffers, H.; Komninos, N. Future Internet and Living Lab Research domain landscape: Filling the gap between technology push and application pull in the context of Smart Cities. In Proceedings of the eChallenges e-2011 Conference, Florence, Italy, 26-28 October 2011.

69. European Parliament-Committee for Industry, Research and Energy, Mapping Smart Cities in the EU. Directorate-General for Internal Policies, Policy Department A: Economic and Scientific Policy; IP/A/ITRE/ST/2013-02, PE 507.480; European Parliament: London, UK, 2014; ISBN 978-92823-4761-4.

70. Bourdieu, P. The forms of capital. In Handbook of Theory and Research for the Sociology of Education; Richardson, J.G., Ed.; Greenwood: New York, NY, USA, 1986; pp. 241-258.

71. Coleman, J.S. Social capital in the creation of human capital. Am. J. Soc. 1988, 94, S95-S120. [CrossRef]

72. Portes, A. Social capital: Its origins and applications in modern sociology. Annu. Rev. Sociol. 1988, $24,1-24$. [CrossRef]

73. Inkpen, A.C.; Tsang, E.W. Social capital, networks, and knowledge transfer. Acad. Manag. Rev. 2005, 30, 146-165. [CrossRef]

74. Adler, P.S.; Kwon, S.W. Social capital: Prospects for a new concept. Acad. Manag. Rev. 2002, $27,17-40$. [CrossRef]

75. Bogers, M.; West, J. Managing distributed innovation: Strategic utilization of open and user innovation. Creat. Innov. Manag. 2012, 21, 61-75. [CrossRef]

76. Chesbrough, H. Open Innovation: The New Imperative for Creating and Profiting from Technology; Harvard Business School Press: Boston, MA, USA, 2003.

77. Schaffers, H.; Komninos, N.; Pallot, M.; Aguas, M.; Almirall, E.; Bakici, T.; Barroca, J.; Carter, D.; Corriou, M.; Fernadez, J.; et al. Smart Cities as Innovation Ecosystems Sustained by the Future Internet. FIREBALL Project Technical Report. 2012, p. 65, HAL Id: hal-00769635. Available online: https://hal.inria.fr/hal-00769635 (accessed on 15 January 2015).

78. Schaffers, H.; Sallstrom, A.; Pallot, M.; Hernández-Muñoz, J.M.; Santoro, R.; Trousse, B. Integrating Living Labs with Future Internet experimental platforms for co-creating services within Smart Cities. In Proceedings of the 17th International Conference on Concurrent Enterprising (ICE), Aachen, Germany, 20-22 June 2011; pp. 1-11.

79. Johnson, S.P.; Menor, L.J.; Chase RB Roth, A.V. A critical evaluation of the new services development process: Integrating service innovation and service design. In New Service Development, Creating Memorable Experiences; Fitzsimmons, J.A., Fitzsimmons, M.J., Eds.; Sage Publications: Thousand Oaks, CA, USA, 2000.

80. Errichiello, L.; Micera, R. City Stakeholder Collaboration in Complex Innovation Project: The Cultural Service System MuseoTorino. In Proceedings of the International Conference on Tourism-ICOT2016, Naples, Italy, 29 June-2 July 2016.

81. Lupo, E.; Özdil, E. Towards a "Smart Heritage" as Future Diffused Museums: Design and Communication Technologies to Innovate the Experience of the Cultural Patrimony in Smart Cities. Int. J. Incl. Mus. 2013, 6, 159-169. [CrossRef]

82. A MuseoTorino il Premio Icom Italia-Musei dell'anno 2011. Available online: http:/ / www.museotorino.it/ resources/content/160276/CS_MuseoTorino_Premio_ICOM_2011.pdf (accessed on 16 May 2018).

83. Gallouj, F.; Weinstein, O. Innovation in services. Res. Policy 1997, 26, 537-556. [CrossRef]

84. Drejer, I. Identifying innovation in surveys of services: A Schumpeterian perspective. Res. Policy 2004, 33, 551-562. [CrossRef]

85. Denzin, N.K. Collecting and Interpreting Qualitative Materials; Sage: Thousand Oaks, CA, USA, 2008; Volume 3.

86. Strauss, A.; Corbin, J.M. Basics of Qualitative Research: Grounded Theory Procedures and Techniques; Sage Publications, Inc.: Thousand Oaks, CA, USA, 1990.

87. Bowen, G.A. Document analysis as a qualitative research method. Qual. Res. J. 2009, 9, 27-40. [CrossRef]

88. Brod, M.; Tesler, L.E.; Christensen, T.L. Qualitative research and content validity: Developing best practices based on science and experience. Qual. Life Res. 2009, 18, 1263. [CrossRef] [PubMed]

89. Creswell, J.W. Research Design: Qualitative \& Quantitative Approaches; Sage Publications, Inc.: Thousand Oaks, CA, USA, 1994. 
90. Miles, M.B.; Huberman, A.M.; Huberman, M.A.; Huberman, M. Qualitative Data Analysis: An Expanded Sourcebook; Sage: Thousand Oaks, CA, USA, 1994.

91. Leech, N.L.; Onwuegbuzie, A.J. An array of qualitative data analysis tools: A call for data analysis triangulation. School Psychol. Q. 2007, 22, 557. [CrossRef]

92. Available online: https:/ / www.museotorino.it (accessed on 20 January 2015).

93. Rivista MuseoTorino, n.0. June 2010. Available online: http://www.museotorino.it/resources/pdf/ magazine/flip/00/ (accessed on 16 May 2018).

94. Calabi, D. Memory, narrative and display-city museums in recent initiatives and debates. Plan. Perspect. 2009, 24, 385-390. [CrossRef]

95. Link, T. Models of sustainability: Museums, citizenship, and common wealth. Mus. Soc. Issues 2006, 1, 173-190. [CrossRef]

96. Newman, A.; McLean, F.; Urquhart, G. Museums and the active citizen: Tackling the problems of social exclusion. Citizsh. Stud. 2005, 9, 41-57. [CrossRef]

97. Rivista MuseoTorino, n.5. December 2012. Available online: http://www.museotorino.it/resources/pdf/ magazine/rivista_mt_05.pdf (accessed on 16 May 2018).

98. Città di Torino Deliberazione Della Giunta Comunale, 25 May 2010. Available online: http://www. museotorino.it/resources/pdf/archive/delibera_approvazione_progetto_2010.pdf (accessed on 16 May 2018).

99. Pencarelli, T.; Cerquetti, M.; Splendiani, S. The sustainable management of museums: An Italian perspective. Tour. Hosp. Manag. 2016, 22, 29-46. [CrossRef]

100. Lehmann, E.E.; Seitz, N.; Wirsching, K. Smart finance for smart places to foster new venture creation. Economia e Politica Industriale 2017, 44, 51-75. [CrossRef]

101. Bakici, T.; Almirall, E.; Wareham, J. A Smart City Initiative: The Case of Barcelona. J. Knowl. Econ. 2013, 4, 135-148. [CrossRef]

102. Lee, J.H.; Hancock, M.G.; Hu, M.C. Towards an effective framework for building smart cities: Lessons from Seoul and San Francisco. Technol. Forecast. Soc. Chang. 2014, 89, 80-99. [CrossRef]

(C) 2018 by the authors. Licensee MDPI, Basel, Switzerland. This article is an open access article distributed under the terms and conditions of the Creative Commons Attribution (CC BY) license (http:/ / creativecommons.org/licenses/by/4.0/). 